\title{
AN EMPIRICAL INVESTIGATION OF THE BLACK-SCHOLES MODEL: EVIDENCE FROM THE AUSTRALIAN STOCK EXCHANGE
}

\author{
Scott McKenzie, Dionigi Gerace, Zaffar Subedar \\ University of Wollongong
}

\begin{abstract}
This paper evaluates the probability of an exchange traded European call option being exercised on the ASX200 Options Index. Using single-parameter estimates of factors within the Black-Scholes model, this paper utilises qualitative regression and a maximum likelihood approach. Results indicate that the Black-Scholes model is statistically significant at the $1 \%$ level. The results also provide evidence that the use of implied volatility and a jump-diffusion approach, which increases the tail properties of the underlying lognormal distribution, improves the statistical significance of the Black-Scholes model.
\end{abstract}

Keywords: Black-Scholes model, probability

\section{INTRODUCTION}

Published in the Journal of Political Economy 1972 Fisher Black and Myron Scholes develop a model to price a European call option written on non-dividend paying stock. Rubinstein, (1994) states the Black-Scholes option pricing model is the most widely used formula, with embedded probabilities, in human history.

Since development of the model authors have consistently searched to test its empiricism ${ }^{1}$. Empirical investigations concede that the Black-Scholes model produces bias in its estimation. The assumptions of a historical instantaneous volatility measure and an underlying lognormal distribution do not hold. Yang (2006) suggests an implied volatility approach. Duan (1999) suggests the tail properties of the underlying lognormal distribution are too small.

One facet of the Black-Scholes model which has received scant attention is the underlying probabilities attributed to the model, in particular the probability that an option will be exercised. The Black-Scholes model estimates the probability of a European call option being exercised through the calculation of $N\left(d_{2}\right)$; which is the probability relating to the strike price. To our knowledge no test seeks to explicitly test the underlying probabilities within the Black Scholes model with evidence from the ASX, providing a future reference to potential model misspecification.

This paper looks to empirically examine the accuracy and statistical significance of the factors within the Black-Scholes model, with evidence from the ASX. The investigation uses qualitative regression; logit and probit models; and a maximum likelihood approach. If as hypothesised the value of $N\left(d_{2}\right)$ is the probability of an option being exercised, factors within the Black Scholes model should exert levels of statistical and economical significance, when regressed on a data sample of ASX option contracts.

\footnotetext{
${ }^{1}$ For empirical dissertation of Black-Scholes model see Bates (1996), Bates (2002), Garcia, Ghysels, and Renault (2002).
} 
The paper is organised as follows. Section 2 reviews the relevant literature of option pricing. Section 3 describes the data used in this investigation. The model is presented and compared to the Black-Scholes model in Section 4. Section 5 presents the empirical results. A conclusion is presented in Section 6.

\section{LITERATURE REVIEW}

Despite the extant literature on the Black-Scholes model the following is a brief review of empirical developments related to the central theme of this paper. Starting with Black and Scholes (1973) empirical investigations conclude bias within the Black-Scholes model in terms of moneyness and maturity. Successive papers document similar bias regardless of boundary conditions ${ }^{2}$.

Studies have also noted volatility bias in the Black-Scholes model. Black and Scholes (1973) using S\&P 500 option index data 1966-1969 suggest the variance that applies over the option produces a price between the model price and market price. Black and Scholes (1973) propose evidence, volatility is not stationary. Galai (1977) confirm Black and Scholes (1973) that the assumption of historical instantaneous volatility need be relaxed.

MacBeth and Merville (1980) compare the Black-Scholes model against the constant elasticity of variance (CEV) model, which assumes volatility changes when the stock prices changes. Empirical evidence of the relationship between the level of stock prices and the rate of volatility is contradictory. Blattberg and Gonedes (1974) suggest volatility of the underlying stock is stochastic and random. Rosenberg (1973) suggests that it follows an autoregressive scheme. Black (1976) suggests that the volatility of the underlying stock varies inversely with stock prices. MacBeth and Merville (1980) found that the volatility of the underlying stock decreases as the stock price rises. Their empirical results are also consistent with the results of Geske (1979).

Beckers (1980) tested the Black-Scholes assumption that the historical instantaneous volatility of the underlying stock is a function of the stock price, using S\&P 500 index options 1972-1977. Beckers (1980) finds the underlying stock is an inverse function of the stock price.

Geske and Roll (1984) show that at an original time both in-the-money and out-of-themoney options contain volatility bias. Geske and Roll (1984) conclude, time and money bias may be related to improper boundary conditions, where as the volatility bias problem may be the result of statistical errors in estimation.

Yang (2006) finds implied volatilities used to value exchange traded call options on the ASX 200 Index are unbiased and superior to historical instantaneous volatility in forecasting future realised volatility.

Literature proposes the Black-Scholes model may underprice options because the tail properties of the underlying lognormal distribution are too small. Rubinstein (1994) illustrates that the implied volatility for S\&P 500 index options exerts excess kurtosis. Shimko (1993) demonstrates that implied distributions of S\&P 500 index are negatively skewed and

\footnotetext{
${ }^{2}$ For empirical investigations of Black-Scholes model see Galai (1977), Finnerty (1978), MacBeth, Merville (1979), Bhattacharya (1980), Gultekin, Rogaiski and Tinc (1982), Geske, Roll and Shastri (1984) among others.
} 
leptokurtic. Jackwerth and Rubinstein (1996) show the distribution of the S\&P 500 before 1987 exert lognormal distributions, but since have deteriorated to resemble leptokurtosis and negative skewness. Several studies seek to increase the tail properties of the lognormal distribution by incorporating a jump-diffusion process or stochastic volatility ${ }^{3}$.

Trautmann and Beinert (1994) estimate parameters of a jump-diffusion process on German capital markets, against the Black-Scholes model. They find option prices generated through a jump-diffusion model are not comparable from those obtained from the BlackScholes model. Amin and Ng (1993) examine the ability of stochastic volatility models which are derived using ARCH. Amin and $\mathrm{Ng}$ (1993) find ARCH models mitigate moneyness and time to maturity bias but not completely.

Das and Sundaram (1999) indicate jump-diffusion and stochastic volatility mitigate but do not eliminate volatility bias. Das and Sundaram (1999) identify jump-diffusion and stochastic volatility processes do not generate skewness and extra kurtosis resembled in reality.

Buraschi and Jackwerth (2001) develop statistical tests based on instantaneous model and stochastic models using S\&P 500 index options data from 1986-1995. Buraschi and Jackwerth (2001) conclude the data is more consistent with models that contain additional risk factors such as stochastic volatility and jump-diffusion.

In summary empirical investigations concede that the Black-Scholes model produces bias in its estimation. The assumptions of a historical instantaneous volatility measure and an underlying lognormal distribution do not hold. The remainder of this paper analyses if violations of the prior apply to the underlying probabilities of the Black-Scholes model.

This paper, in analysing the probability of an exchange traded option being exercised on the ASX, extends the extant literature is several respects, given that scant literature exists regarding the probability within the Black Scholes model. This study provides one of the few studies which explicitly examine the models underlying probabilities with evidence from the ASX. Furthermore, in contrast from previous work which studies the Black-Scholes model in broad terms, this paper contributes by investigating the statistical significance of each individual factor within the model.

\section{DATA}

The ASX options market which opened 3 February, 1976 was the first exchange traded options market outside of North America. The market offers fully electronic, deep, liquid markets with average volume exceeding 100,000 contracts a day, representing trade value of $\$ 250$ billion per annum (ASX, 2006).

Securities Industry Research Centre of Asia-Pacific (SIRCA) provided prices of 159 ASX 200 Index option contracts, matched underlying ASX 200 stock prices and risk free interest rates for the period February 2003 to July 2007. For each observation the approximated option and underlying stock price were calculated as the average of the last bid

\footnotetext{
${ }^{3}$ For jump-diffusion process see Naik and Lee (1990), Bates (1991), Bates (1996), Rubinstein (1994), Chen and Palmon (2005). For stochastic volatility see Heston (1993), Hull and White (1987), Johnson and Shanno (1987), Scott (1997), Wiggens, (1987).
} 
and ask quotes. The risk free interest rate was observed from the 90-day Australian government T-Bill rate quoted on the issue date of the option.

In this paper; we acknowledge historical instantaneous volatility produces bias in its estimation. To ensure robustness in our results three different measures of volatility are used; historical instantaneous (V1), actual instantaneous (V2), and implied volatility (V3). The instantaneous measures are given by standard deviation of the underlying stock returns;

$$
\sigma=\sqrt{\frac{1}{n-1} \sum_{i=1}^{n}\left(u_{i}-\bar{u}\right)^{2}}
$$

where $\bar{u}$ is the sample mean, expressed as;

$$
\bar{u}=\frac{1}{n} \sum_{j-1}^{u} u_{j}
$$

where the annualising factor $(\mathrm{h})$ is expressed as the annual number of trading days on the ASX, such that $h$ is equal to 252 .

$$
\sigma_{a n}=\sigma * \sqrt{h}
$$

The implied volatility is the value of $\sigma$ that when substituted into Black Scholes model equates the price of the option to the observed market price.

$$
\begin{gathered}
C=S 0 N\left(d_{1}\right)-K e^{-R F T} N(d 2) \\
d_{1}=\frac{\ln (S 0 / K)+\left(R F+\sigma^{2} / 2\right) T}{\sigma \sqrt{T}} \\
d_{2}=\frac{\ln (S 0) / K)+\left(R F-\sigma^{2} / 2\right) T}{\sigma \sqrt{T}}=d_{1}-\sigma \sqrt{T}
\end{gathered}
$$

It is impossible to invert the Black-Scholes equation so that $\sigma$ is expressed as a function of S0, K, T, RF and C. A root finding technique is implemented to calculate implied volatility.

\section{THE MODEL}

This paper utilises a logistic distribution which increases the tails properties of the lognormal distribution. Logistic distributions have been used in work by Draper and Smith (1981), Peiro (1994), Aparico and Estrada (2001).

The logistic and lognormal distributions are similar, except they are based upon different significance levels (Gujarati, 2003). The fatter tails of the logistic distribution suggest that the conditional probability approaches 0 and 1 at a slower rate than the lognormal distribution (Gujarati, 2003). 
Under a logistic distribution, the estimated probability that an option will be exercised at maturity will be lower than that of the lognormal distribution at levels greater than $50 \%$ and lower at levels less then $50 \%$.

\section{Figure-1 Logistic and lognormal underlying distributions}

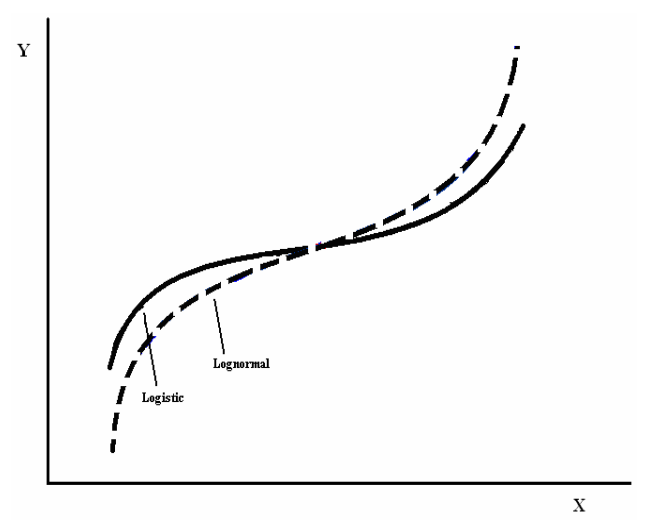

Essentially the investigation of this paper can be expressed in binary form where $\mathrm{Y}$ is a Bernoulli variable (Gujarati, 2003). If the option is exercised at maturity then $\mathrm{Y}=1$ or not exercised $\mathrm{Y}=0$. This paper utilises qualitative regression models; logit and probit and maximum likelihood approach to explicitly test the statistical significance of the BlackScholes model with ASX observations.

The logit model specification based upon a logistic distribution is as follows; $\mathrm{Y}=1$ if the option is exercised at maturity and 0 if it is not;

$$
\begin{gathered}
\mathrm{P}_{i}=\left(Y=1 \mid S O, K, T, R F, V_{i}\right)=F\left(\beta_{0}+\beta_{1} S O+\beta_{2} K+\beta_{3} T, \beta_{4} R F+\beta_{5} V_{i}\right) \\
=\frac{1}{1+e^{-\left(\beta_{0}+\beta_{1} S O+\beta_{2} K+\beta_{3} T, \beta_{4} R F+\beta_{5} V_{i}\right)}}
\end{gathered}
$$

where $\mathrm{P}_{i}$ probability that option $i$ is exercised at maturity. $\mathrm{Y}$ is a binary dependant variable; $\mathrm{F}$ is the lognormal distribution function; S0 represents the price of the underlying stock; $\mathrm{K}$ represents the strike price; $\mathrm{T}$ represents time to maturity; RF represents the risk free rate; $V_{i}$ represents each volatility measure $(V 1, V 2, V 3) ; \beta_{i}$ is coefficient of the regressor.

The probit model specification based upon the lognormal distribution is as follows: $\mathrm{Y}$ $=1$ if the option is exercised at maturity and 0 if it is not;

$$
\mathrm{P}_{i}=\left(Y=1 \mid S O, K, T, R F, V_{i}\right)=\phi\left(\beta_{0}+\beta_{1} S O+\beta_{2} K+\beta_{3} T+\beta_{4} R F+\beta_{5} V_{i}\right)
$$

where $\mathrm{P}_{i}$ probability that option $i$ is exercised at maturity. $\mathrm{Y}$ is a binary dependant variable; $\phi$ is lognormal cumulative distribution function; S0 represents price of the underlying stock; $\mathrm{K}$ represents the strike price; $\mathrm{T}$ represents time to maturity; RF represents the risk free rate; $V_{i}$ represents each volatility measure $(V 1, V 2, V 3)$; and $\beta_{i}$ is the coefficient of the regressor. 
The two-stage least squares regression involves two successive regression applications. The first stage regression is the qualitative regression model. Recall;

The logit model estimation;

$$
\mathrm{P}_{i}=\left(Y=1 \mid \text { So }, K, T, R f, V_{i}\right)=F\left(\beta_{0}+\beta_{1} S o+\beta_{2} K+\beta_{3} T, \beta_{4} R f+\beta_{5} V_{i}\right)
$$

The probit model estimation;

$$
\mathrm{P}_{i}=\left(Y=1 \mid S o, K, T, R f, V_{i}\right)=\phi\left(\beta_{0}+\beta_{1} S o+\beta_{2} K+\beta_{3} T+\beta_{4} R f+\beta_{5} V_{i}\right)
$$

The outlined models above decompose $\mathrm{P}_{i}$ into two components; a problematic component that may be correlated with the error term and another problem-free component that is uncorrelated with the error term (Stock et al., 2003). The second stage uses the problem free component to estimate the level of $\beta_{1}$ (Stock et al 2003). Essentially the level of $\beta_{1}$ tests the statistical significance of each regression model without the problematic component. The specifications of the second stage least squares model;

$$
R_{i, t}=\beta_{0}+\beta_{1} \hat{\mathrm{P}}_{i}+\beta_{2} R_{i, t-1}
$$

where $R_{i, t}$ is return of the underlying stock $i$ at time $t . \hat{P}_{i}$ is estimated probability from each model. $R_{i, t-1}$ is lagged return on the underling stock $i$ at time $t-1 . \beta_{i}$ is the coefficient of the regressor.

\section{RESULTS}

The logit and probit models express $Y=1$ if the call option was exercised and $Y=0$ if not. The independent variables used in the qualitative regression analysis are the factors used in the Black Scholes model; the price of the underlying stock (S0); the strike price of the option $(\mathrm{K})$; the time left to maturity expressed as a percentage of the number of ASX trading days $(\mathrm{T})$; the risk free interest rate $(\mathrm{RF})$; the historical instantaneous volatility (V1); actual instantaneous volatility (V2) and the implied volatility (V3). Each qualitative regression model is estimated using the method of maximum likelihood. The results of the qualitative regression are given in tabular form in Table- 1 and Table- 2 respectively. The second stage least squares results are given in Table-3. All regressions are estimated using SAS software.

Since the logit model is estimated using maximum likelihood method the estimated standard errors are asymptotic (Gujarati, 2003). Instead of using the t-statistic to evaluate the statistical significance of a coefficient the (standard normal) z-statistic is used (Stock et al 2003).

The estimated model is highly significant at the $1 \%$ level using the likelihood ratio and associated p-values. The McFadden $\mathrm{R}^{2}$ ranges between 0.184 (column 1) and 0.185 (column 2 and 3), whilst the count $R^{2}$ ranges from 0.723 (column 1 and 2) to 0.730 (column 3) indicating that between $72-73 \%$ of options actually exercised on the ASX were estimated correctly by the logit model.

Each of the slope coefficients in the logit model is a partial slope coefficient and measures the change in estimated logit model for a unit change in the value of the given 
regressor (Gujarati, 2003). Thus, S0 coefficient in the first regression estimate in Table 5-1 of 0.7475 means, with other variables held constant, that if S0 increases by a unit on average the estimated logit model increases by about 7.475 units, suggesting a positive relationship between the two.

Table-1 Logit Model $\mathrm{P}_{i}=\left(Y=1 \mid S O, K, T, R F, V_{i}\right)=F\left(\beta_{0}+\beta_{1} S O+\beta_{2} K+\beta_{3} T, \beta_{4} R F+\beta_{5} V_{i}\right)$

Columns represent three regression estimates. Dependant variable; the payoff of the option at maturity; 1 if exercised; 0 if not exercised. Mean standard errors of each coefficient are in parenthesis; SO is the initial price of the underlying stock; $\mathrm{K}$ is the option strike price; $\mathrm{T}$ is the time left to maturity expressed as a percentage of the number of ASX trading days; RF is the risk free interest rate; V1 is the historical volatility of the underlying stock price prior to the option life; V2 is the actual volatility of the underlying stock price over the option life; V3 is the implied volatility; LR is the likelihood ratio at 5 degrees of freedom.

\begin{tabular}{|c|c|c|c|}
\hline Explanatory Variables & $(1)$ & $(2)$ & (3) \\
\hline Intercept & $\begin{array}{l}-6.6134 * \\
(3.7479)\end{array}$ & $\begin{array}{c}-6.8813^{*} \\
(3.7809)\end{array}$ & $\begin{array}{l}-6.4564 * \\
(3.7738)\end{array}$ \\
\hline $\mathrm{SO}$ & $\begin{array}{l}0.7475^{* * *} \\
(0.2101)\end{array}$ & $\begin{array}{l}0.7553^{* * *} \\
(0.2109)\end{array}$ & $\begin{array}{l}0.7454 * * * \\
(0.2069)\end{array}$ \\
\hline K & $\begin{array}{l}-0.7048 * * * \\
(0.2008)\end{array}$ & $\begin{array}{l}-0.7104 * * * \\
(0.2015)\end{array}$ & $\begin{array}{l}-0.7029 * * * \\
(0.1977)\end{array}$ \\
\hline $\mathrm{T}$ & $\begin{array}{l}1.9455^{* * *} \\
(0.5718)\end{array}$ & $\begin{array}{l}1.9737 * * * \\
(0.5750)\end{array}$ & $\begin{array}{l}1.9070 * * * \\
(0.5766)\end{array}$ \\
\hline $\mathrm{RF}$ & $\begin{array}{l}107.1126 * * \\
(66.9243)\end{array}$ & $\begin{array}{l}109.0983^{\text {*** }} \\
(68.2495)\end{array}$ & $\begin{array}{l}\text { 105.7904* } \\
(68.0872)\end{array}$ \\
\hline V1 & $\begin{array}{l}0.0484 \\
(0.3866)\end{array}$ & $\begin{array}{l}- \\
-\end{array}$ & $\begin{array}{l}- \\
-\end{array}$ \\
\hline V2 & - & $\begin{array}{l}0.3538 \\
(0.6661)\end{array}$ & - \\
\hline V3 & - & - & $\begin{array}{l}0.4099 \\
(1.0226)\end{array}$ \\
\hline LR statistic (5 df) & 36.477 & 36.646 & 36.706 \\
\hline$p$-value & 0.000 & 0.000 & 0.000 \\
\hline McFadden $\mathrm{R}^{2}$ & 0.184 & 0.185 & 0.185 \\
\hline Count $\mathrm{R}^{2}$ & 0.723 & 0.723 & 0.730 \\
\hline Sample size & 159 & 159 & 159 \\
\hline
\end{tabular}

As table 5-1 shows all the other regressors except the option strike price (K) have a positive effect on the logit model, indicating all variables are economically significant. The intercept and risk free interest rate are statistically significant at the $10 \%$ level, all other variables except the volatility measures are statistically significant at the $1 \%$ level. Each volatility measure (V1, V2, and V3) are statistically insignificant suggesting that volatility has no impact on the probability of a European call option being exercised on the ASX. However together all the regressors have a significant impact on the estimated probability, the LR statistic of each equation is between 36.477 and 36.706 and the p-values $<0.0001$.

Each of the slope coefficients in the probit model is a partial slope coefficient and measures the change in estimated probit model for a unit change in the value of the given regressor. Thus, the S0 coefficient in the first regression estimate in Table 5-2 of 0.4191 
means, with other variables held constant, that if S0 increases by a unit on average the estimated probit model increases by about 4.191 units, suggesting a positive relationship between the two. It must be noted that although the probit and logit model are similar their estimated coefficients are not directly comparable

Table-2 Probit Model $\mathrm{P}_{i}=\left(Y=1 \mid S O, K, T, R F, V_{i}\right)=\phi\left(\beta_{0}+\beta_{1} S O+\beta_{2} K+\beta_{3} T, \beta_{4} R F+\beta_{5} V_{i}\right)$

Columns represent three regression estimates. Dependant variable; the payoff of the option at maturity; 1 if exercised; 0 if not exercised. Mean standard errors of each coefficient are in parenthesis; SO is the initial price of the underlying stock; $\mathrm{K}$ is the option strike price; $\mathrm{T}$ is the time left to maturity expressed as a percentage of the number of ASX trading days; RF is the risk free interest rate; V1 is the historical volatility of the underlying stock price prior to the option life; V2 is the actual volatility of the underlying stock price over the option life; V3 is the implied volatility; LR is the likelihood ratio at 5 degrees of freedom.

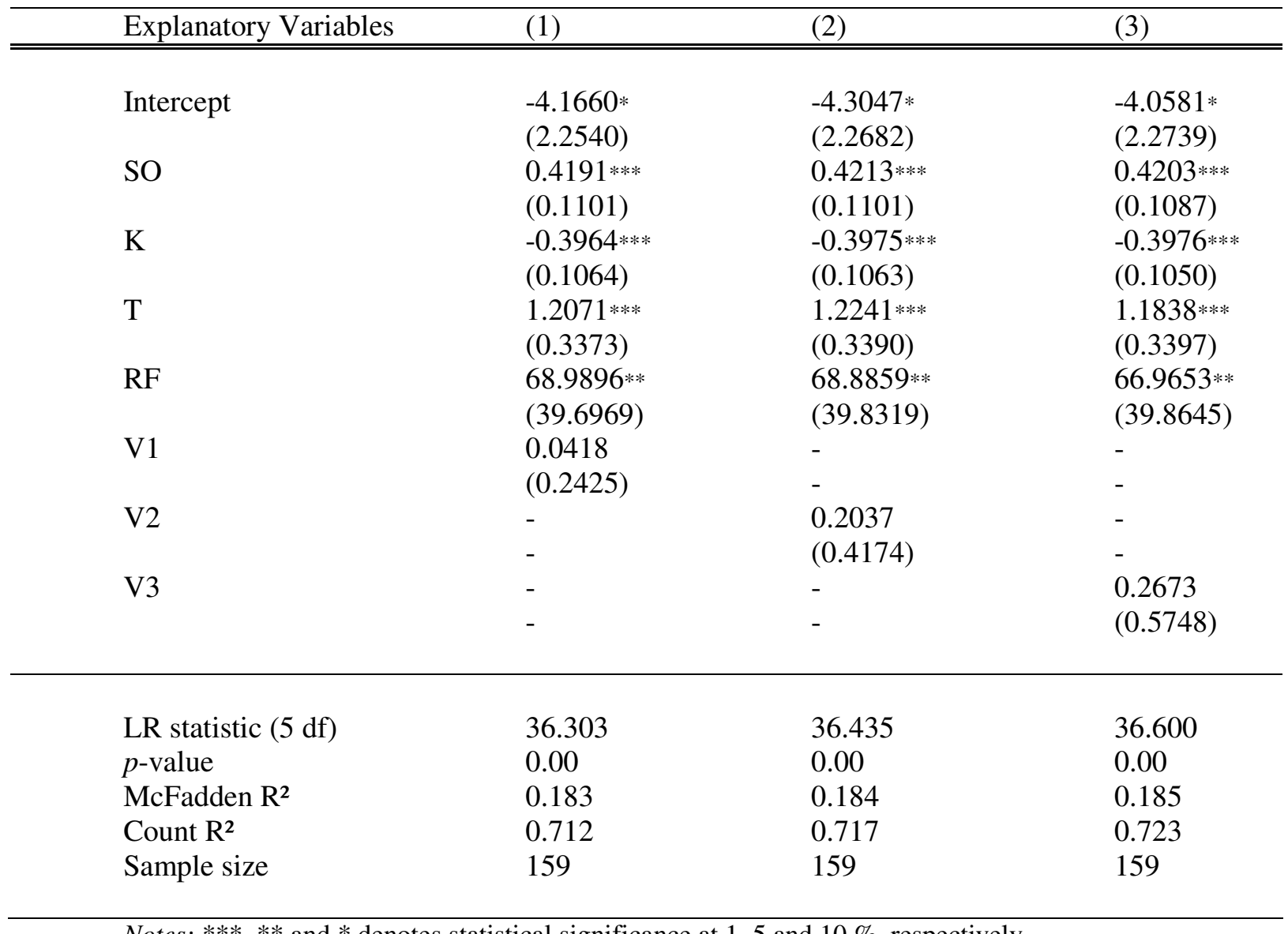

Notes; ***, ** and $*$ denotes statistical significance at 1,5 and $10 \%$, respectively.

The estimated model is again highly significant at the $1 \%$ level using the likelihood ratio and associated p-values. The McFadden $\mathrm{R}^{2}$ ranges between 0.183 (column 1) and 0.185 (column 3), whilst the count $\mathrm{R}^{2}$ ranges from 0.712 (column 1) and 0.723 (column 3), indicating that between $71-72 \%$ of options actually exercised on the ASX were estimated correctly by the probit model.

As Table 5-2 shows all the other regressors except the option strike price $(\mathrm{K})$ have a positive effect on the probit model, suggesting all coefficients are economically significant. The intercept and risk free interest rate are statistically significant at the $10 \%$ level and, all other variables except the volatility measures are statistically significant at the $1 \%$ level. Each volatility measure (V1, V2, and V3) are statistically insignificant. However together all the 
regressors have a significant impact on the estimated model as the LR statistic of each equation is between 36.303 (column 1) and 36.600 (column 3), p-values $<0.0001$.

When analysing between the logit and probit regressions, analysis of the diagnostics of each equation in Table 5-5 and 5-6 is essential. The LR statistic of each model show, that the logistic models display a higher LR statistic for each equation than under the probit model. This confirms the literature of Duan (1999) that the Black Scholes model produces more significant results when the tail properties of the underlying distribution are increased. These results are also applicable against the McFadden $\mathrm{R}^{2}$ and count $\mathrm{R}^{2}$.

The diagnostics within each model that implied volatility is superior to historical volatility and historical volatility over the option is superior to historical volatility prior to the option. These results are confirmed via the size of the LR statistics as well as the McFadden $\mathrm{R}^{2}$ and count $\mathrm{R}^{2}$ measures. This confirms the work of Yang (2006) that implied volatility is superior to historical volatility in estimation of the Black-Scholes model.

\section{Table-3 Second Stage Least Squares. $R_{i, t}=\beta_{0}+\beta_{1} \hat{\mathrm{P}}_{i}+\beta_{2} R_{i, t-1}$}

Dependant variable is return of the underlying asset; $\mathrm{P}$ is the estimated probability values of each probit regression model; R2 is the lagged return on the underlying stock price. V1 is the historical volatility of the underlying stock price prior to the option life; V2 is the actual volatility of the underlying stock price over the option life; V3 is the implied volatility; $\phi$ is the lognormal distribution; $\mathrm{F}$ is the logistic distribution.

\begin{tabular}{lccccc}
\hline & \multicolumn{2}{c}{$\mathrm{V} 1$} & \multicolumn{2}{c}{$\mathrm{V} 2$} & $\mathrm{~V} 3$ \\
\cline { 2 - 6 } & $\phi$ & $\mathrm{F}$ & $\phi$ & $\mathrm{F}$ & $\phi$ \\
\hline \hline \multirow{2}{*}{ Intercept } & $-0.0311^{* * *}$ & $-0.0305^{* * *}$ & $-0.0298^{* * *}$ & $-0.0294 * * *$ & $-0.0305^{* * *}$ \\
& $(0.0099)$ & $(0.0297)$ & $(0.0099)$ & $(0.0100)$ & $(0.0298)$ \\
$\mathrm{P}$ & $0.0305^{* * *}$ & $0.0297^{* * *}$ & $0.0290^{* * *}$ & $0.0283^{* * *}$ & $0.0298^{* * *}$ \\
& $(0.0122)$ & $(0.0122)$ & $(0.0122)$ & $(0.0122)$ & $(0.0122)$ \\
$\mathrm{R} 2$ & -0.0041 & -0.0041 & -0.004 & -0.004 & -0.0041 \\
& $(0.0062)$ & $(0.0062)$ & $(0.0062)$ & $(0.0062)$ & $(0.0062)$ \\
& & & & \\
\hline Obs. & 159 & 159 & 159 & 159 \\
\hline
\end{tabular}

Essentially the level of $\beta_{1}$ tests the statistical significance of each of the regression models without the problematic component within the error terms (Stock et al 2003). Analysis of statistical significance of $\beta_{1}$ in each qualitative regression model displays statistical significance at the $1 \%$ level. Illustrating each of the regression models is statistically significant with the problematic component of the error term omitted. Further the economic significance of $\beta_{1}$ is confirmed through the sign of the coefficient which is positive indicating the higher the return of the underlying stock, the higher the expected value of $\mathrm{P}_{i}$ (Copeland, 2005). 


\section{CONCLUSION}

The results of this paper indicate that the Black Scholes model is relatively accurate. Comparing the qualitative regression models provides evidence that the Black Scholes model is significant at the $1 \%$ level in estimating the probability of an option being exercised. All variables of each regression model exert expected signs of economical significance. The results based on a method of maximum likelihood indicate that the factors of the BlackScholes collectively are statistically significant. However at the individual level neither historical volatility nor implied volatility is statistically significant. Indicating, measures of volatility are irrelevant in estimating the probability of an option being exercised. Conversely, the Black-Scholes model under the use of implied volatility is superior instantaneous volatility, with actual instantaneous superior to historical instantaneous volatility, confirming the work of Yang (2006).

The qualitative regression models also illustrates the significance of the Black-Scholes model under a logistic distribution is superior to a lognormal distribution. Indicating that the use of a jump-diffusion approach increases the tail properties of the lognormal distribution increases the statistical significance of the Black-Scholes model. These results are concurrent with the work of Duan (1999).

The second stage least squares approach to test significance of the qualitative regression models provides significance at the $1 \%$ level. Omitting the error term of each qualitative regression retains statistical significance at the $1 \%$ level. Each qualitative regression model exerts robustness which ensures that inferences drawn from each regression hold. Further the results suggest that no factors other than those used in the Black-Scholes model dramatically affect the probability of an option being exercised.

Like all empirical inquires, this paper has a number of limitations. The first issue considers the time series of the data. To ensure robustness a four year time series was employed. Consequently using a shorter time series may produce qualitatively different results. Consequently conducting the time series at a shorter interval may produce bias with reference to industry shocks. Another potential issue relates to the estimated measures of volatility. Whilst the measure of volatility was guided by previous empirical research and a single-parameter approach, future research may consider using a multi-parameter approach. An approach based upon ARCH or VAR which estimates volatility using lagged volatility measures may improve the results. This may introduced either a unit root or multicollinearity since volatility will be dependant upon lagged estimates. Furthermore, additional model specifications beyond the factors within the Black-Scholes model may be considered.

\section{REFERENCES}

Amin, K. I., and Ng, V. K. (1993). Inferring future volatility from the information in implied volatility Eurodollar options: A new approach. Review of financial studies, 10(2), 333-367.

Aparico, F. M., and Estrada, J. (2001). Empirical distributions of stock returns: European securities markets, 1990-95. European Journal of finance, 7(1), 1-21.

Australian Stock Exchange (2006). Derivatives and your company: How options and warrants can increase liquidity and lower volatility of your shares. Publications ASX.

Bates, D. S. (1991). The crash of 87: Was it expected? The evidence from option markets. Journal of finance, 46, 1009-1044.

Bates, D. S. (1996). Jumps and stochastic volatility: exchange rate process implicit in PHLX deutsche mark options. Review of financial studies, 9(1), 69-107

Bates, D. S. (2002). Empirical options pricing: A retrospection. University of Iowa and the National Bureau of Economic Research. 
Beckers, S. (1980). The constant elasticity of variance model and its implications for option pricing. Journal of finance, 35(3), 661-673.

Bhattacharya, M. (1980). Empirical properties of the Black Scholes formula under ideal conditions. Journal of financial and quantitative analysis, 15(5), 1081-1105.

Black, F. (1976). Fact of fantasy in the use of options. Financial analysis journal, 31, 36-41, 61-72.

Black, F., and Scholes, M. (1972). The valuation of option contracts in a test of market efficiency. Journal of finance, 27(3), 399-417

Black, F., and Scholes, M. (1973). The pricing of options and corporate liabilities, Journal of political economy, 81(4), 637-659.

Blattberg, R. C., and Gonedes, J. (1974). A comparison of the stable and student distributions as statistical models for stock prices. Journal of business, 47(2), 244-280.

Buraschi, A., and Jackwerth, J. (2001). The price of a smile: Hedging and spanning in option markets. Review of financial studies, 14(2), 495-527.

Chen, R., and Palmon, O. (2005). A Non-Parametric Options Pricing Model: Theory and Empirical Evidence. Review of Quantitative Finance and Accounting, 24(1), 115-134.

Copeland, T., Weston, J., and Shastri, K. (2005). Financial theory and corporate policy (4 ed.). New York: Pearson Addison Wesley.

Das, S. R., and Sundaram, R. K. (1999). Of Smiles and Smirks: A Term Structure Perspective. Journal of financial and quantitative analysis, 34(2), 211-239.

Draper, N. \& Smith, H. (1981). Applied Regression Analysis (2nd edn). New York: Wiley.

Duan, J. C. (1999). Conditionally fat tailed distribution and the volatility smile in options. University of Toronto, working paper.

Dumas, B., Fleming, J., and Whaley, R. E. (1998). Implied volatility functions: empirical tests. Journal of finance, 53(6), 2059-2106

Finnerty, J. E. (1978). The Chicago Board Options Exchange and market efficiency. Journal of finance and quantitative analysis, 13(1), 29-38.

Galai, D. (1977). Tests of market efficiency of the Chicago Board Options Exchange. Journal of business, 50(2), 167-197.

Geske, R. (1979). The valuation of compound options. Journal of financial economics 7(1), 63-81.

Geske, R., R, Roll., and Shastri, K. (1984). Over-the-counter option market dividend protection and "Biases" in the Black-Scholes model: A note. Journal of finance, 38, 1271-1277.

Garcia, R. E., Ghysels, E., and Renault, E. (2002). The econometrics of option pricing, University of Montreal working paper.

Gujarati, D. (2003). Basic econometrics (4 ed.). New York: McGraw-Hill.

Gultekin, N. B., Rogalski, J. R., and Tinc S. M. (1982). Option pricing model estimates: Some empirical results. Financial management, 11(1), 58-69.

Heston, S. (1993), A Closed-Form Solution for Options with Stochastic Volatility with Applications to Bond and Currency Options, Review of financial studies, 6, 327-343.

Hull, J., and White, A. (1987). The Pricing of Options on Assets with Stochastic Volatilities. Journal of finance 42(2), 281-300.

Jackwerth J. C., and Rubinstein, M. (1996). Recovering probability distributions from option prices. Journal of finance, 51(5), 1611-1631.

Johnson, H., and Shanno, D. (1987). Option pricing when the variance is changing. Journal of financial and quantitative analysis. 22(2) 143-151.

Macbeth, J. D., and Merville, L. J. (1979). An empirical examination of the Black-Scholes Call option pricing model. Journal of finance, 34(5), 1173-1186.

MacBeth, J. D., and Merville, L. J. (1980). Tests of the Black-Scholes and Cox call option valuation models. Journal of finance, 35(2), 285-301.

Naik, V., and Lee M. (1990). General equilibrium: Pricing of options on the market portfolio with discontinuous return. Review of financial studies, 3, 493-521.

Peiro, A. (1994). The distribution of stock returns: International evidence. Applied financial economics, 4(6), 431-439.

Rosenberg, B. (1973). The behaviour of random variables with nonstaionary variance and the distribution of security prices. University of California, Berkeley, Manuscript.

Rubinstein, M. (1983). Displaced diffusion option pricing. Journal of finance, 38(1), 213-217.

Rubinstein, M. (1994). Implied Binomial Trees. Journal of finance 49(3), 771-818.

Scott, L. O. (1997). Pricing stock options in a jump-diffusion model with stochastic volatility and interest rates: Applications of Fourier inversion methods. University of Georgia working paper

Shimko, D. (1993). Bounds of probability. Risk 6, 33-37.

Stock, J. H., and Watson, M. W. (2003). Econometrics (3 ed.). London: Addison Wesley. 
The Australasian Accounting Business \& Finance Journal, December, 2007. McKenzie, Gerace \& Subedar: Empirical Investigation of the Black-Scholes Model. Vol. 1, No. 4.

Page 82.

Trautmann, S., and Beinert, M. (1994). Stock price jumps and their impact on option valutation. Johannes Gutenberg Universitat, Mainz, Germany working paper.

Wiggens, J. B. (1987). Option values under stochastic volatility: theory and empirical estimations. Journal of financial economics, 351-372.

Yang, Q. (2006). An empirical study of implied volatility in Australian index option market. Queensland University of Technology working thesis,. 